\title{
Review Article \\ Shelf Life of Extra Virgin Olive Oil and Its Prediction Models
}

\author{
Xueqi Li $\mathbb{D}^{1}$ and Selina C. Wang $\mathbb{D}^{1,2}$ \\ ${ }^{1}$ University of California Davis Olive Center, Davis, CA 95616, USA \\ ${ }^{2}$ Department of Food Science and Technology, University of California, Davis, Davis, CA 95616, USA \\ Correspondence should be addressed to Selina C. Wang; scwang@ucdavis.edu
}

Received 26 October 2017; Accepted 2 January 2018; Published 31 January 2018

Academic Editor: Amani Taamalli

Copyright (C) 2018 Xueqi Li and Selina C. Wang. This is an open access article distributed under the Creative Commons Attribution License, which permits unrestricted use, distribution, and reproduction in any medium, provided the original work is properly cited.

Extra virgin olive oil (EVOO), with high unsaturation degree (oleic acid, linoleic acid, and linolenic acid), is prone to oxidation during production and storage even with the presence of abundant antioxidants (e.g., phenolic compounds, alpha-tocopherol, and chlorophyll). The level of oxidation degradation is greatly affected by the EVOO chemical composition (free fatty acids, saturated and unsaturated fat ratio, total phenol content, etc.) and storage conditions (packaging material, oxygen, temperature, and light). With the increasing demand on qualitative acceptability and food safety of an EVOO product, consumers rely heavily on "shelf life" as a good indicator. Hence, it is critical for olive oil producers to provide accurate and practical information on shelf-life prediction. This review analyzes ten shelf-life prediction models that used various parameters and approaches for model establishment. Due to the complexity of chemical interactions between oil phase and environment under real-time storage and rapid accelerated testing conditions, further investigation is needed to scrutinize and minimize the discrepancies between real-time shelf life and predicted shelf life of EVOO products.

\section{Introduction}

Known as a key component in the Mediterranean diet for centuries, extra virgin olive oil (EVOO) has become globally recognized and appreciated by consumers due to its unique sensory characteristics and high nutritional values. In recent years, there has been considerable interests in correlating monounsaturated fatty acids (mainly oleic acid) and minor components (phenolic compounds, alpha-tocopherol and carotenoids, squalene, simple triterpenes, and volatile compounds) in EVOO with health benefits \{e.g., antihypertensive activity [1], chemopreventive activity [2], tumor-inhibitory activity [3], and anti-inflammatory activity [4]\} and positive sensory attributes [5-7]. However, due to high levels of unsaturated fatty acids and the presence of endogenous enzymes such as lipase, polyphenol oxidase, and peroxidase, EVOO is also prone to lipid oxidation and enzymatic hydrolysis which favors autoxidation [8-10]. EVOO oxidation is highly dependent on factors including the storage of olive fruit prior to processing [11], the techniques of oil extraction [12], the exposure degree of oxygen, light, and temperature [13], and the packaging [14] and storage conditions of the final product [15], which could greatly change the chemical composition of the oil, leading to unpleasant off-flavors and eventually degrading the quality.

For consumers, one of the most important characteristics in EVOO is freshness, as freshness is typically associated with high quality and ensures food safety [16]. The term "shelf life" is commonly referred to when determining the freshness and consumer acceptability of EVOO [17]. Specifically, EVOO shelf life could be defined as the length of time under normal storage conditions within which no off-flavors or defects are developed and quality parameters are within accepted limits for this commercial category [18]. Consumers rely on shelflife determinations to differentiate between products that are acceptable for consumption from those that are no longer acceptable. Thus, it is obligatory for the olive oil industry to monitor oil quality throughout the production line [19] and to be able to provide realistic information on shelf-life prediction considering the temperature changes and light exposure during transport and commercial activities [20].

EVOO shelf-life testing is often conducted under realtime conditions or accelerated conditions [21]. Real-time shelf-life testing allows data collection under normal storage 
conditions and reflects actual changes in EVOO matrix over time [22]. On the other hand, this process requires consistent storage conditions and can be extremely time consuming when the quality depletion of EVOO proceeds fairly slowly under normal storage conditions [21]. Hence, accelerated shelf-life testing (ASLT) methods such as Rancimat, Active Oxygen Method (AOM), and Oil Stability Index (OSI) are also employed to determine EVOO shelf life under conditions which are different from normal storage conditions within a short period of time [23]. Noticeably, as convenient and rapid as the accelerated methods can be, Kaya et al. [24] reported that extrapolation from the Rancimat values led to either underprediction or overprediction of the actual shelf life of sunflower and olive oil due to drastic ASLT conditions. Nonetheless, analytical data generated from either or both conditions can be applied to the development of EVOO shelflife prediction models.

In general, two types of shelf-life prediction models are widely used to simulate EVOO degradation: kinetic models and empirical models. Kinetic models are developed based on how reaction rates in critical chemical parameters (Table 1) are influenced by experimental conditions related to variables such as storage time, temperature, and light [20]. Data describing the changes of these parameters under conditions simulating actual storage are submitted to modeling based on the known rate of a particular reaction. The limitation of kinetic modeling is that classical kinetic equations cannot easily accommodate the complexity of oxidation reactions and oil deteriorations. Empirical models are developed based on the correlations between individual chemical parameters and experimental condition variables. Typically, advanced statistical analyses are performed on analytical data to develop regression models which enable the prediction of maximum shelf life as a function of chemical parameters $[20,25]$. The limitation of empirical modeling is the difficulty to extend beyond the measured setup (e.g., storage condition) and simplification and approximation can fail when the setup is changed.

Previous studies have been done intensively on how different ratios of chemical composition, packaging systems, and storage conditions would affect the quality of EVOO $[14,26-31]$. However, the olive oil industry is still in great need of practical and effective shelf-life prediction models that can be easily used or adopted after moderate modifications in order to reasonably predict EVOO shelf life and to ensure the EVOO products complying with the current regulations for its category [32].

In this review, ten shelf-life prediction models using various parameters and approaches are discussed. In addition, future directions of shelf-life prediction models are proposed aiming at minimizing the discrepancies between real-time shelf life and predicted shelf life of EVOO products.

\section{Prediction Models for EVOO Shelf-Life Determination}

The development process of EVOO shelf-life prediction models is streamlined in Figure 1. While ASLT provides a more rapid and less-expensive method of predicting shelf life than real-time storage condition monitoring, some accelerated conditions may lead to erroneous shelf-life predictions because of complicated chemical reaction mechanisms from real-time conditions [33]. Thus, shelf-life prediction models are best developed based on results from both real-time and accelerated storage conditions, followed by extensive evaluation and adjustment.

Table 2 provides a summary of olive oil sample size, chemical/sensory analysis, and statistical approach of the ten shelf-life prediction models discussed in this review.

\subsection{Pagliarini et al. (2000) [20]. This Tuscan EVOO shelf-life} prediction model used induction time, hydroxytyrosol, and tyrosol to predict the time (in days) to reach an acceptable limit of 2.1 for UV $K_{232}$.

The research team analyzed a total of 37 samples from five different lots which are categorized in Table 3. The samples were subjected to different bottling, transport, and storage conditions in supermarkets, although the authors found that the stability of the oil was not significantly affected. This could be due to reasons that (1) the oil was stored properly in the tanks at processing facility in Italy (OL.MA.) before getting bottled; (2) the oil did not experience extreme travel stress during transportation to either Italian supermarket or Australia supermarket; (3) while the oil was stored in supermarkets, the uncontrolled light and temperature were still in favor of maintaining the quality of olive oil.

The research team tracked the changes in oil during storage with 21 physiochemical parameters and sensory analysis and via multivariate analysis procedure, it was concluded that the most significant parameters were $K_{232}$, induction time, chlorophyll, carotenoid, alpha-tocopherol, hydroxytyrosol, and tyrosol. Since the only parameter that had established limit in the standards was $K_{232}$, three empirical models were set up to predict the time to reach a given value for $K_{232}$ and 2.1 was chosen as a reference value:

$$
\begin{aligned}
& \text { (a) } t=1130.84 \operatorname{Ln} \text { (induction time) }-2388.13 \\
& \text { (b) } t=329.02-38.11 \text { (hydroxytyrosol) } \\
& \text { (c) } t=580.34-68.11 \text { (tyrosol) }
\end{aligned}
$$

In these equations $t$ is the time (in days) to reach an acceptable limit of 2.1 for $K_{232}$. According to the authors, this model underestimates the experimental storage time by 20 days for Rancimat induction time, 10 days for hydroxytyrosol content, and 5 days for tyrosol content.

The above models could be useful for selecting new olive/oil suppliers and comparing different suppliers, olive harvest years, and storage conditions. While these three equations consist of simple calculations, the output of estimated time is when $K_{232}$ reaches 2.1 instead of 2.50 which is the upper limit of $K_{232}$ for EVOO category in the International Olive Council (IOC) trade standard [32]. Hence, the results may not be reflective and reliable in their current form.

2.2. Gutiérrez and Fernández (2002) [35]. The quality indices (specified in the European Union standards EC1991 Regulation 2568/91) of EVOO samples produced from two 
TABLE 1: Critical chemical parameters used in olive oil shelf-life prediction model development.

\begin{tabular}{llcl}
\hline Parameter & Determination & Indicator & Methodology \\
\hline Free fatty acids (FFA) & $\begin{array}{c}\text { Free fatty acids are formed by the } \\
\text { hydrolysis of triglycerides during } \\
\text { ripening, processing and storage }\end{array}$ & $\begin{array}{c}\text { An elevated level of free fatty acid } \\
\text { indicates hydrolyzed fruits } \\
\text { and/or poor quality oil made } \\
\text { from unsound fruit, improperly } \\
\text { processed or stored oil }\end{array}$ & Analytical titration \\
\hline
\end{tabular}

Peroxides are primary oxidation products that are formed when Peroxide value (PV) oils are exposed to oxygen, producing undesirable flavors and aroma

Conjugated double bonds are formed from natural

Ultraviolet absorbance (UV) nonconjugated unsaturation in oils upon oxidation. The $K_{232}$ measures primary oxidation products and $K_{270}$ measures secondary oxidation products

Fresh EVOO contains a high proportion of 1,2-diacylglycerols to 1,2- and 1,3-diacylglycerols, while olive oil from poor quality fruits and refined olive oils have higher level of 1,3-DAGs than fresh EVOO

1, 2-Diacylglycerols (DAGs)

Chlorophyll pigments break Pyropheophytins (PPP) down to pheophytins and then pyropheophytins upon thermal degradation and aging of olive oil

\begin{tabular}{|c|c|c|c|}
\hline Sensory evaluation & $\begin{array}{l}\text { Sensory refers to flavor and } \\
\text { aroma attributes }\end{array}$ & $\begin{array}{l}\text { Sensory evaluation can help } \\
\text { identify oils that are of poor } \\
\text { quality, oxidized, and/or } \\
\text { adulterated with other oils }\end{array}$ & $\begin{array}{c}\text { A recognized panel of } 8-12 \\
\text { people evaluates oils for sensory } \\
\text { characteristics }\end{array}$ \\
\hline Induction time & $\begin{array}{l}\text { The oxidation process is } \\
\text { accelerated by means of heating } \\
\text { up the reaction vessel while } \\
\text { passing air continuously through } \\
\text { the sample }\end{array}$ & $\begin{array}{l}\text { Oxidative stability (in hours) } \\
\text { denotes the resistance of oils to } \\
\text { oxidation. The longer the } \\
\text { induction time, the more stable } \\
\text { the oil }\end{array}$ & Rancimat \\
\hline Total phenols & $\begin{array}{c}\text { The sum of up to } 30 \text { individual } \\
\text { phenols which have antioxidative } \\
\text { ability }\end{array}$ & $\begin{array}{l}\text { A low level of total phenols can } \\
\text { indicate a shorter shelf life while } \\
\text { a high level of total phenols can } \\
\text { indicate a longer shelf life }\end{array}$ & $\begin{array}{l}\text { UV spectrophotometry/High } \\
\text { performance liquid } \\
\text { chromatography (HPLC) }\end{array}$ \\
\hline $\begin{array}{l}\text { Volatiles (e.g. } \\
\text { hexanal/nonanal, } \\
\text { E-2-hexenal/hexanal), }\end{array}$ & $\begin{array}{c}\text { Volatile compositions change } \\
\text { during oxidation. For example, as } \\
\text { the oil oxidizes, the } \\
\text { concentration of hexanal } \\
\text { decreases while concentration of } \\
\text { nonanal increases }\end{array}$ & $\begin{array}{l}\text { The ratios of hexanal/nonanal } \\
\text { and E-2-hexenal/hexanal can } \\
\text { indicate oxidized oil }\end{array}$ & $\begin{array}{l}\text { Headspace-gas chromatography } \\
\text { (GC) }\end{array}$ \\
\hline $\begin{array}{l}\text { Fatty acid profile } \\
\text { (FAP) }\end{array}$ & $\begin{array}{l}\text { Saturated and unsaturated fatty } \\
\text { acids consist of the principal } \\
\text { components of fats. Fatty acid } \\
\text { profiles are distinguishable } \\
\text { markers between olive oils and } \\
\text { some seed/nut oils (FAPs vary } \\
\text { slightly depending on the } \\
\text { varieties and growing region of } \\
\text { olives) }\end{array}$ & $\begin{array}{l}\text { Analysis of the fatty acid profile } \\
\text { provides information on the } \\
\text { authenticity of the olive oil and } \\
\text { can be used as an indicator for } \\
\text { adulteration }\end{array}$ & Gas chromatography (GC) \\
\hline
\end{tabular}

An elevated level of peroxides indicates oxidized and/or poor quality oil
Analytical titration

An elevated level of UV

absorbance indicates oxidized and/or poor quality oil
UV spectrophotometry

A low ratio of 1,2-diacylglycerols

to 1,2- and 1,3-diacylglycerols is

an indicator for oil that is

hydrolyzed, oxidized, and/or of poor quality
Gas chromatography (GC)

An elevated ratio of pheophytin a to pyropheophytins is an indicator for oil that is oxidized and/or adulterated with refined oil

High performance liquid chromatography (HPLC)

Sensory evaluation can help dentify oils that are of poor quality, oxidized, and/or adulterated with other oils

Oxidative stability (in hours)

notes the resistance of oils to oxidation. The longer the e, the more A low level of total phenols can ndicate a shorter shelf life while high level of total phenols can The ratios of hexanal/nonanal E-2-hexenal/hexanal can indicate oxidized oil (GC) 


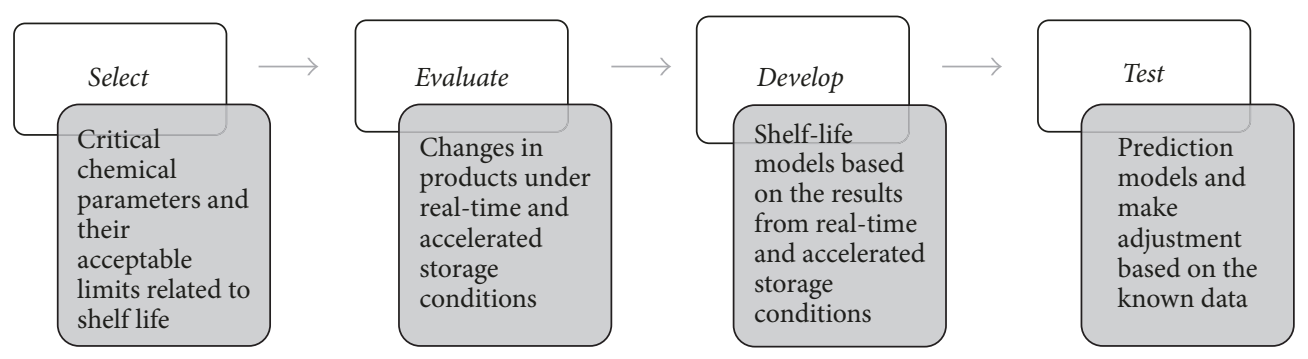

FIGURE 1: Shelf-life prediction model development process.

cultivars, Picual and Hojiblanca, were monitored throughout two different storage conditions, together with the evolution of the oxidative stability and sterols, polyphenols, alphatocopherol, chlorophyllic and carotenoid pigments, and FAP.

In this study, a total of $46 \mathrm{~L}$ of EVOO was extracted and packed for each cultivar in Spain. Thirty-four $1 \mathrm{~L}$ transparent glass bottles of each cultivar were stored inside a thermostated chamber at $30^{\circ} \mathrm{C}$ with illumination $(800 \mathrm{~lx} ; 12 \mathrm{~h} /$ day), which was similar to commercial storage conditions. Other twelve bottles of each cultivar were stored at $2^{\circ} \mathrm{C}$ in darkness. In addition, $30 \mathrm{~L}$ EVOO of each cultivar was purchased in a local market as commercial reference samples and stored in the thermostated room. Bottles were sampled weekly during the first 70 days and subsequently every 15 days for 6 months of storage. It is worth mentioning that the EVOO samples produced from each cultivar had similar initial values on most of the chemical parameters other than acidity (Picual: 0.44\%; Hojiblanca: 0.26\%), stability (Picual: $69.5 \mathrm{~h}$; Hojiblanca: $43.3 \mathrm{~h}$ ), and $o$-diphenols (Picual: $9.00 \mathrm{mg} / \mathrm{kg}$; Hojiblanca: $14.64 \mathrm{mg} / \mathrm{kg}$ ).

Overall, samples stored at $2^{\circ} \mathrm{C}$ in darkness remained minimal to unaltered throughout the entire storage period. Thus, the regression analysis was performed on selected chemical parameters from samples stored at $30^{\circ} \mathrm{C}$ with illumination for each cultivar (Table 3). Similar changes in PV of two olive cultivars were observed in a 2 -fold increase during the first 21 days and followed by a linear decrease until the end of storage. The evolutions of alpha-tocopherol, chlorophyllic pigments (CP), total polyphenols (TP), and $o$-diphenols were well fitted to first-order kinetics. Most importantly, the coefficient $K_{270}$, which measures the accumulation of secondary oxidation products that cause off-flavors in olive oil, showed a sharp increase along the storage period in all the samples stored at $30^{\circ} \mathrm{C}$ with illumination in spite of cultivar and sample source. As a result, an excellent correlation between initial stability and time to reach the limit of $K_{270}=0.25$ was established for EVOO samples bottled in glass containers regardless of olive cultivar (Table 4).

The correlation between initial stability $(S)$ and storage time to achieve $K_{270}$ of 0.25 has demonstrated when an EVOO no longer retains its extra virgin quality. Being a critical indicator of oxidation level, $K_{270}$ is required by the IOC standard [32] and can be easily obtained by producers. Nonetheless, the validation of this model is in need for other cultivars with a larger sample size in an extended storage period. Storage containers other than glass type should also be taken into consideration when applying this model.
2.3. Psomiadou et al. (2003) [19]. To establish this empirical model, fifty-two Greek virgin olive oil (VOO) samples (Koroneiki cv) from three consecutive crops (1994-1997) were obtained as the training set for quality parameters measurement. The measured parameters included FFA, PV, UV, FAP, and the ratio of unsaturated and saturated fatty acids, alpha-tocopherol, total phenols, total chlorophylls, and OSI. Collinearity diagnostics, variable selection, and regression analysis were performed on the obtained analytical data to determine the contribution of each parameter to maintaining VOO quality.

Through statistical analyses, the research team located alpha-tocopherol, PV, total chlorophylls, and total phenols to be the most important factors that affected OSI values and yielded below model:

$$
\begin{aligned}
\text { OSI }= & 5.081+0.0102 \text { (alpha-tocopherol) } \\
& -0.364(\mathrm{PV})+0.0477 \text { (total chlorophylls) } \\
& +0.0259 \text { (total phenols) }
\end{aligned}
$$

As shown in the above model, all antioxidants contributed in a similar way to the OSI factor while PV posed clear negative impact on the oxidative stability of the oil. The predictability of this model was further examined and confirmed by a test set of 13 VOO samples of the same cultivar from 1999-2000 crop, which showed a negligible prediction bias and a low square root of the mean square error of 2.33, indicating an effective prediction of OSI was achieved in this model for VOO of Koroneiki $c v$.

In this study, the effect of many oxidative parameters on oils from different crop years was examined with comprehensive statistical analyses, yielding a simple predictive equation, and followed by validation on another 13 samples from the same cultivar. However, while this model gives useful information regarding the oil stability which impacts shelf life directly, it would require producers to incur the expense for three tests (alpha-tocopherol, total phenols, and total chlorophylls) that are not currently required in the standards [32]. Besides, producers can request OSI analysis (by Rancimat) for less of the cost than these three tests although the correlation between OSI and actual shelf life was not elaborated. Regardless, this model still has practical influence on the routine control of Koroneiki $c v$ VOO in the industry and future development of prediction models for VOO made from other olive cultivars can be derived from this validated model with minor modifications. 


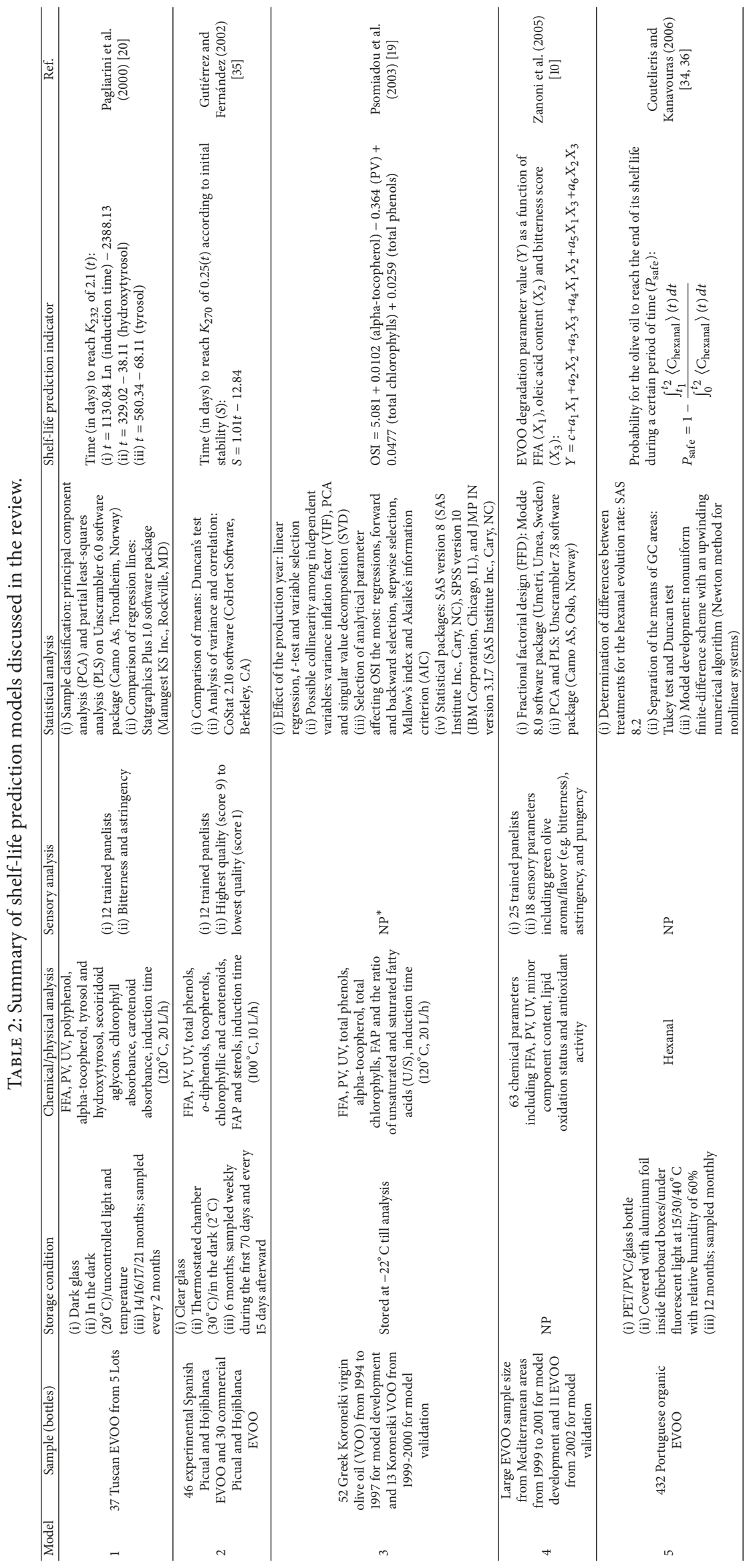




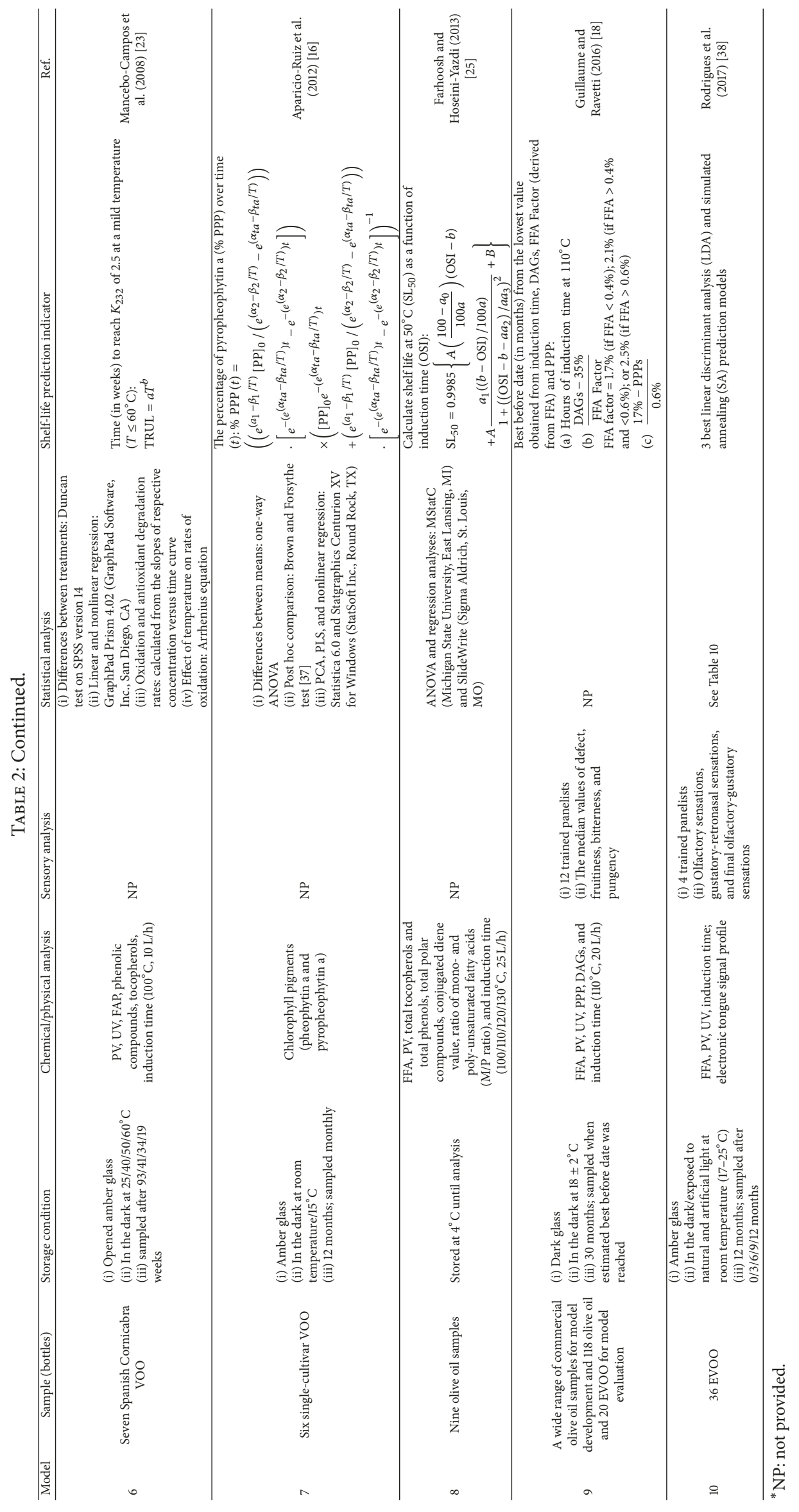


TABLE 3: Sample Lot information in the Pagliarini et al. (2000) model.

\begin{tabular}{lccccc}
\hline Lot \# & $\begin{array}{c}\text { Lot } A \\
\text { (reference lot) }\end{array}$ & Lot $B_{1}$ & Lot $B_{2}$ & Lot $C_{1}$ & Lot $C_{2}$ \\
\hline $\begin{array}{l}\text { Time taken from } \\
\text { freshly made batch }\end{array}$ & $\begin{array}{c}\text { Immediately after } \\
\text { processing }\end{array}$ & $\begin{array}{c}\text { After 77 days of } \\
\text { storage in tanks }\end{array}$ & $\begin{array}{c}\text { After 188 days of } \\
\text { storage in tanks }\end{array}$ & $\begin{array}{c}\text { After 98 days of } \\
\text { storage in tanks }\end{array}$ & $\begin{array}{c}\text { After 188 days of } \\
\text { storage in tanks }\end{array}$ \\
\hline $\begin{array}{l}\text { Bottling } \\
\text { closed with screw } \\
\text { caps }\end{array}$ & $\begin{array}{c}500 \mathrm{~mL} \text { dark glass, } \\
\text { closed with screw } \\
\text { caps }\end{array}$ & $\begin{array}{c}500 \mathrm{~mL} \text { dark glass, } \\
\text { closed with screw } \\
\text { caps }\end{array}$ & $\begin{array}{c}500 \mathrm{~mL} \text { dark glass, } \\
\text { closed with screw } \\
\text { caps }\end{array}$ & $\begin{array}{c}500 \mathrm{~mL} \text { dark glass, } \\
\text { closed with screw } \\
\text { caps }\end{array}$ \\
\hline $\begin{array}{l}\text { Shipping } \\
\text { destination after } \\
\text { bottling }\end{array}$ & $\begin{array}{c}\text { Processing facility } \\
\text { in Italy (OL.MA.) }\end{array}$ & $\begin{array}{c}\text { A supermarket in } \\
\text { Australia }\end{array}$ & $\begin{array}{c}\text { A supermarket in } \\
\text { Australia }\end{array}$ & $\begin{array}{c}\text { A supermarket in } \\
\text { Italy (close to } \\
\text { OL.MA.) }\end{array}$ & $\begin{array}{c}\text { A supermarket in } \\
\text { Italy (close to } \\
\text { OL.MA.) }\end{array}$ \\
\hline $\begin{array}{l}\text { Storage condition } \\
\text { at destination }\end{array}$ & In the dark at 20 ${ }^{\circ} \mathrm{C}$ & $\begin{array}{c}\text { Uncontrolled light } \\
\text { and temperature }\end{array}$ & $\begin{array}{c}\text { Uncontrolled light } \\
\text { and temperature }\end{array}$ & $\begin{array}{c}\text { Uncontrolled light } \\
\text { and temperature }\end{array}$ & $\begin{array}{c}\text { Uncontrolled light } \\
\text { and temperature }\end{array}$ \\
\hline $\begin{array}{l}\text { Storage period at } \\
\text { destination }\end{array}$ & 21 months & 16 months & 14 months & 17 months & 14 months \\
\hline
\end{tabular}

TABLE 4: Correlations between storage time $t$ (in days) and selected parameters by Gutiérrez and Fernández (2002).

\begin{tabular}{lcc}
\hline Cultivar & Picual & Hojiblanca \\
\hline PV (mequiv/kg) & $\mathrm{PV}=-0.04 t+7.2 ;$ & $\mathrm{PV}=$ \\
& $r=0.9532$ & $\begin{array}{c}-0.03 t+6.6 ; \\
r=0.9600\end{array}$ \\
\hline & $\mathrm{Ln}(\% \mathrm{TP})=$ & $\mathrm{Ln}(\% \mathrm{TP})=$ \\
$\mathrm{TP}(\mathrm{mg} / \mathrm{kg}$, caffeic acid) & $-4.45 \times 10^{-3} t+2.03 ;$ & $-2.55 \times 10^{-3} t+$ \\
& $r=0.9879$ & $1.97 ; r=0.9965$ \\
\hline & $\mathrm{Ln}(\mathrm{CP})=$ & $\mathrm{Ln}(\mathrm{CP})=$ \\
$\mathrm{CP}(\mathrm{mg} / \mathrm{kg})$ & $-0.11 t+12.34 ;$ & $-0.26 \mathrm{t}+18.92 ;$ \\
& $r=0.9848$ & $r=0.9810$ \\
\hline Initial stability $(S)$ for the & \multicolumn{2}{c}{} \\
achievement of $K_{270}=0.25$ & $S=1.01 t-12.84 ; r=0.9823$ \\
(h) & & \\
\hline
\end{tabular}

2.4. Zanoni et al. (2005) [10]. A phenomenological model was introduced for the first time to predict the stability of EVOO based on combined stability/instability composition indices. The experimental design comprised two steps: (1) stability/instability indices screening and (2) significant relationships between screened indices and EVOO degradation investigation and confirmation. The screening of composition indices was carried out by multivariate analysis on data derived from 63 chemical and 18 sensory parameters obtained from oils purchased from four different Mediterranean area during the 1999-2001 crops. Based on the statistical analysis, the research group proposed that acidity value was indirectly related to oil stability while oleic acid content and bitter taste were directly related to oil stability. The predictability of these most relevant indices to oil stability was then checked by measuring six major degradation parameters on eleven oil samples differing in screened indices planned by a fractional factorial design (FFD) and processed with principal component analysis (PCA) and partial least squares (PLS) regression afterward. Parameters of PV, UV, minor polar component content (oleuropein and ligstroside derivatives), oxidative status of fatty acids, antioxidant activity, and sensory evaluation were measured in this step.
Combining the results from PCA mapping and PLS modeling has proved the hypothesis that in EVOO samples (1) the more acidity the more degradation; (2) the more oleic acid content the less degradation; and (3) the more bitter the taste the less the degradation. Furthermore, PV, UV $K_{232}$, and lipid oxidation status (oxidized fatty acid content at $230 \mathrm{~nm}$ and dienoic and trienoic conjugated fatty acids content) were found to be the most critical parameters when measuring EVOO degradation. A mathematical model was established to predict EVOO degradation as a function of the combination of the three most relevant indices (acidity, oleic acid content, and bitter taste):

$$
\begin{aligned}
Y= & c+a_{1} X_{1}+a_{2} X_{2}+a_{3} X_{3}+a_{4} X_{1} X_{2}+a_{5} X_{1} X_{3} \\
& +a_{6} X_{2} X_{3},
\end{aligned}
$$

where $Y$ is the selected degradation parameter to be predicted, $X_{1}$ is the acidity, $X_{2}$ is the oleic acid content, and $X_{3}$ is bitter taste score. Constant values $a_{x}$ are listed in Table 5 . Unlike what had been found in previous studies $[19,20$, 35], the antioxidant component content which consisted of antioxidant activity and minor polar component content in this study showed insignificant impact on EVOO degradation and was excluded from the proposed model as a result.

Predictive models of oil degradation degree can be obtained based off of the above proposed mathematical model, which may be useful to predict the rate of oil degradation if the oil degradation history was known. In this regard, a major limitation of this model is that it was based on constant indices without taking the composition changes under storage conditions into full consideration. That is, any changes of oil composition that occurred during lipid oxidation would require a new set of quality index values to maintain the model validation. Although this drawback may be overcome by replicating the experimental design several times, the application of this model may be limited to EVOO samples being stored under optimal conditions that have minimal effects on the change of stability/instability indices and/or samples that yield similar rate of degradation kinetics for the same stability/instability indices combination. 
TABLE 5: Constant values of selected degradation parameters for empirical polynomial models by Zanoni et al. (2005) [10].

\begin{tabular}{lccccccc}
\hline Degradation parameter & $c$ & $a_{1}$ & $a_{2}$ & $a_{3}$ & $a_{4}$ & $a_{5}$ & $a_{6}$ \\
\hline PV & -77.921 & 115.143 & 1.148 & 28.910 & -1.411 & -3.679 & -0.367 \\
$K_{232}$ & -6.364 & 10.911 & 0.106 & 2.981 & -0.133 & -0.328 & -0.037 \\
Lipid oxidation status & & & & & & \\
$\quad$ Dienoic trans-trans & -0.051 & -0.103 & 0.002 & 0.136 & 0.002 & -0.040 & -0.001 \\
$\quad$ Dienoic cis-trans, trans-cis & 0.990 & -0.510 & 0.006 & 0.054 & 0.023 & -0.262 & -0.002 \\
$\quad$ Trienoic conjugated fatty acid content & -1.562 & 2.960 & 0.020 & 0.563 & -0.034 & -0.183 & -0.006 \\
$\quad$ Oxidized fatty acid content at 230 nm & -0.280 & 4.805 & 0.032 & 1.164 & -0.054 & -0.099 & -0.020 \\
\hline
\end{tabular}

TABLE 6: Sample packaging and storage conditions for a 12-month study in the Coutelieris and Kanavouras (2006) model.

\begin{tabular}{|c|c|c|c|}
\hline Sample & \multicolumn{3}{|c|}{ Portuguese organic EVOO } \\
\hline Packaging material & $0.5 \mathrm{~L}$ PET bottle & 0.5 L PVC bottle & 0.5 L glass bottle \\
\hline Oxygen transmission rate at $0.21 \mathrm{~atm}$ driving force $\left(\mathrm{cc} / \mathrm{m}^{2} /\right.$ day $)$ & 8 & 9.8 & N/A \\
\hline Storage location & \multicolumn{3}{|c|}{$\begin{array}{l}\text { Half covered with aluminum foil inside fiberboard boxes; half } \\
\text { exposed to fluorescent light }\end{array}$} \\
\hline Storage temperature $\left({ }^{\circ} \mathrm{C}\right)$ & \multicolumn{3}{|c|}{15,30 , and 40} \\
\hline Relative humidity (\%) & \multicolumn{3}{|c|}{60} \\
\hline
\end{tabular}

2.5. Coutelieris and Kanavouras (2006) [34, 36]. As listed in Table 1, volatile compounds are good indicators of olive oil quality as they are mainly produced through lipoxygenase pathway and chemical oxidation during processing and storage and contribute greatly to the olive oil flavor [39]. In this study, the evolution of hydroperoxide in the packaged Portuguese organic EVOO samples was monitored and the progression of hexanal, which was assumed as the most prominent volatile compound posing higher impact on the sensory attributes of olive oil, was quantified over a 12-month storage period. Table 6 shows the packaging materials and storage conditions of analyzed EVOO samples.

A mathematical model for the mass transfer taking place in the oil-package material interacting system was deduced based on four assumptions in the oil phase and two assumptions in the oil-package system. In the oil phase, the assumptions were (1) the oil quiescent; (2) all the hydroperoxides eventually transformed to hexanal during lipid oxidation; (3) at time $(t)=0$, there was a measurable amount of oxygen, fatty acid, and hexanal in the oil phase; and (4) the packaging materials adsorbed hexanal according to Langmuir isotherm. In the oil-package system, the assumptions included the following: (1) oxygen and hexanal had constant concentration outside the bottles at spatial coordinate $(x)=0$; and (2) at $t=0$, oxygen and hexanal concentrations inside the packaging material were zero. The mass transfer phenomena were elaborated explicitly by using diffusion equations for diffusion of oxygen and hexanal and Langmuir-type adsorption for hexanal adsorption in the oil-package (cylinder bottle) system. A numerical algorithm, along with a nonuniform finite-difference scheme, was then applied with modifications to solve the issue of nonlinearity of the studied system for various combinations of the storage conditions mentioned in Table 6.

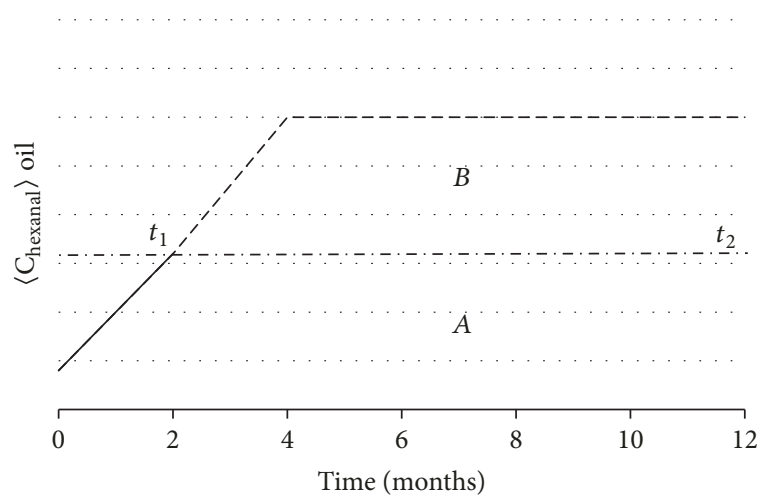

Figure 2: The graphical representation of the definition of $P_{\text {safe }}$. The threshold of the hexanal concentration is represented by the long dash dot line \{adopted from Coutelieris and Kanavouras (2006) [34]\}.

The study showed that samples kept under light had yielded much higher concentration of hexanal when compared to the samples stored in dark. In addition, the highest hexanal concentration was found in samples stored in PET bottles at $40^{\circ} \mathrm{C}$ with light exposure, followed by those stored in glass, and samples stored in PVC bottles had a lower hexanal concentration. As shown in Figure 2, $P_{\text {safe, the }}$ probability for the olive oil to reach the end of its shelf life during a certain time period is comparable to the ratio of the areas below (area A) and above (area B) a roughly defined threshold of the hexanal concentration (long dash dot line). The estimation of $P_{\text {safe }}$ was proposed in the following model during the same time period $\left[t_{1}, t_{2}\right]$ :

$$
P_{\text {safe }}=1-\frac{\int_{t_{1}}^{t_{2}}\left\langle C_{\text {hexanal }}\right\rangle(t) d t}{\int_{0}^{t_{2}}\left\langle C_{\text {hexanal }}\right\rangle(t) d t},
$$


where $C_{\text {hexanal }}$ is the concentration of hexanal, $t_{1}$ is the time when concentration reaches the upper limit for the oil's quality acceptance, $t_{2}$ is set to 12 months in this study, and the brackets indicate spatial averaging of hexanal concentration being used.

The sensitivity of this model was tested on samples kept under different storage conditions and $P_{\text {safe }}$ values were compared for four different thresholds $(15 \%, 20 \%, 25 \%$, and $30 \%$ over the initial hexanal concentration). One of the key findings suggested that the predictions diverged from experimental results under specific storage conditions due to the low concentrations of hexanal in oil stored in dark at any temperature. Moreover, the determination of hexanal concentration threshold was ambiguous without knowing data generated from additional chemical analyses and sensory evaluation. Most importantly, the amount of hexanal does not always allow oxidized olive oils to be distinguished from virgin ones, as this compound can come from both lipoxygenase and oxidative pathways [40]. Nonetheless, the proposed model had undertaken a comprehensive and extensive investigation on the EVOO degradation in the oilpackage system by factoring in the chemical reactions and diffusion of compounds both in the oil phase and through packaging materials, granting a promising parameter for better monitoring the shelf life of packaged olive oil stored under various conditions. The validation of $P_{\text {safe }}$ model can be further strengthened by adding sensory analysis.

2.6. Mancebo-Campos et al. (2008) [23]. During the storage of seven Cornicabra $c v$ VOO samples (varied in total phenol concentrations) in dark and at mild temperatures $(25,40$, 50 , and $60^{\circ} \mathrm{C}$ ), the autoxidation kinetic behavior of the main oxidation indices ( $\mathrm{PV}, K_{232}$, and $\left.K_{270}\right)$ and the oxidizing substrate [unsaturated fatty acids (UFA)] were reported for the first time. In addition, the extrapolated time (in weeks) required to reach the upper limit (TRUL) of each main oxidation index in the EU regulation for the VOO category was also calculated based on the experimental results from this study and a previous study conducted by the same research group [41].

According to the evolution of measurements in this study, PV did not reach its upper limit $(20 \mathrm{meq} / \mathrm{kg})$ in any samples stored at $25^{\circ} \mathrm{C}$ by the end of a 93-week storage, nor did it do that in some of the samples stored at higher temperatures. Stabilization of PV was reached below or slightly above the limit in all cases in spite of more harsh storage temperatures and intensive air exposure in opened bottles. This similar observation was also confirmed by other research groups as a reduction in PV would occur due to the breakdown of peroxides into secondary products $[15,42]$, indicating the unreliability of PV being used as a quality marker for olive oil shelf life. On the contrary, the upper limit of $K_{232}\left(2.5 \mathrm{~K}^{1 \%}{ }_{1 \mathrm{~cm}}\right)$ was reached in samples stored at any conditions although $K_{232}$ and $\mathrm{PV}$ tended to stabilize at a similar value in each sample stored at higher temperatures, following pseudo zeroorder kinetics before reaching the plateau. On the other hand, the upper limit of $K_{270}\left(0.22 \mathrm{~K}_{1 \mathrm{~cm}}\right)$ was reached in all samples with only two exceptions at $25^{\circ} \mathrm{C}$, yielding pseudo

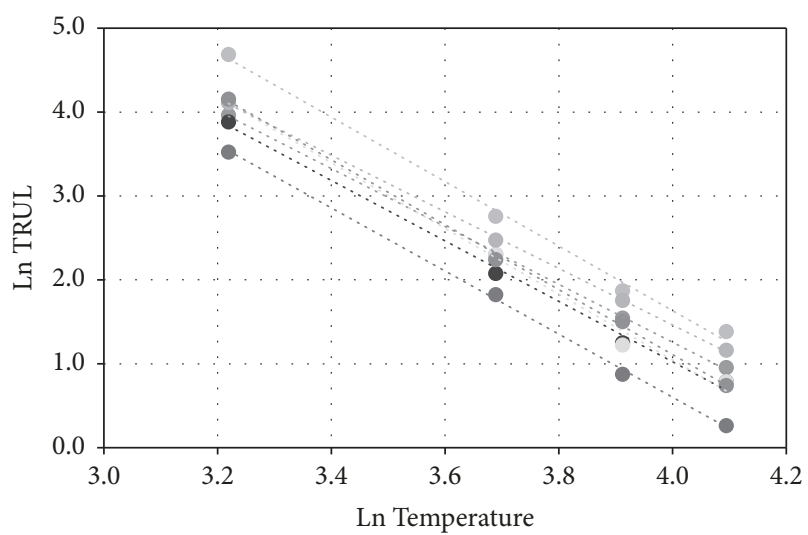

FIgURE 3: Correlation between TRUL and temperature for $K_{232}$ $\left(\right.$ TRUL $\left.=a T^{b}\right)$. Seven samples denoted in seven shades \{adopted from Mancebo-Campos et al. (2008) [23]\}.

first-order kinetics. Furthermore, the polyunsaturated fatty acids (PUFA) linoleic and linolenic acids showed a linear decrease at a rate increasing with storage temperature, and the best correlation was drawn between loss of PUFA and increase of $K_{232}$ at all temperatures as described by the linear Arrhenius equation.

As a good indicator of primary oxidation level and an easy parameter to determine, $K_{232}$ showed high linearity in the early stages of oxidation and presented excellent correlation with loss of UFA. Thus, $K_{232}$ was selected as the best normalized oxidation index for potential shelf-life estimation of VOO, defined as TRUL, at a mild temperature $\left(\leq 60^{\circ} \mathrm{C}\right)$ :

$$
\text { TRUL }=a T^{b} .
$$

Based on the TRUL results of $K_{232}$ generated at different temperatures, the above model can be further explained by Figure 3. As a result, the predicted TRUL at $25^{\circ} \mathrm{C}$ was very close to the experimental TRUL at the same temperature when applying the proposed model to accelerated storage temperatures $\left(40,50\right.$ and $\left.60^{\circ} \mathrm{C}\right)$.

Unlike drastic ASLT conditions where olive oil samples are tested on oxidative stability at over $100^{\circ} \mathrm{C}[43,44]$, this model conducts an accelerated stability test at mild temperatures below $60^{\circ} \mathrm{C}$ and allows a time-saving shelf-life prediction to reasonably estimate the actual shelf life of VOO samples stored under normal storage conditions $\left(25^{\circ} \mathrm{C}\right)$. It is worth noting that VOO samples were stored in open bottles throughout the study with intensive oxygen exposure, which did not reflect the actual storage conditions from a commercial standpoint. Besides, VOO samples used in this study were from the same cultivar with similar initial concentrations on the majority of the measured parameters. A follow-up study focusing on the contribution of antioxidants content and fatty acids unsaturation degrees to oxidation rates is also necessary to test the applicability of the proposed model. 
2.7. Aparicio-Ruiz et al. (2012) [16]. Chlorophyll pigments are sensitive to small amounts of degradation, which would eventually take place in an EVOO even under optimal storage conditions. During storage, pheophytin a (PP) degrades to PPP (Table 1). The ratio of these two compounds therefore is a useful parameter to track olive oil degradation over time. This kinetic prediction model is established based on PPP because PPP changes predictably with time under specific temperatures [45].

In developing this model, the research team stored six single-cultivar VOO samples (Blanqueta $c v$, Arbequina $c v$, Cornicabra $c v$, and Picual $c v$ ) in $65 \mathrm{~mL}$ amber glass jars with
$3 \%(\mathrm{v} / \mathrm{v})$ headspace, in the dark at room temperature. The monthly temperatures range from $10.4^{\circ} \mathrm{C}$ to $28.6^{\circ} \mathrm{C}$ throughout the year, with an average annual temperature of $19.3 \pm$ $1.9^{\circ} \mathrm{C}$. Chlorophyll pigments were quantified every month up to one year. The degradation of PP was found fitting firstorder kinetics after applying multivariate statistical analysis to the experimental data. The statistical results also showed that time, temperature, and initial PP concentration were the main variables that affected PPP prediction for shelf life. Percent PPP (\% PPP) over time was defined as the quotient of the concentration of PPP ([PPP]) and the sum of [PPP] and $[\mathrm{PP}]$. A mathematical model to predict \% PPP as a function of time and temperature was then developed as shown below:

$$
\% \operatorname{PPP}(t)=\frac{\left(e^{\left(a_{1}-\beta_{1} / T\right)}[\mathrm{PP}]_{0} /\left(e^{\left(\alpha_{2}-\beta_{2} / T\right)}-e^{\left(\alpha_{t a}-\beta_{t a} / T\right)}\right)\right)\left[e^{-\left(e^{\left(\alpha_{t a}-\beta_{t a} / T\right)}\right) t}-e^{-\left(e^{\left(\alpha_{2}-\beta_{2} / T\right)}\right) t}\right]}{[\mathrm{PP}]_{0} e^{-\left(e^{\left(\alpha_{t a}-\beta_{t a} / T\right)}\right) t}+\left(e^{\left(a_{1}-\beta_{1} / T\right)}[\mathrm{PP}]_{0} /\left(e^{\left(\alpha_{2}-\beta_{2} / T\right)}-e^{\left(\alpha_{t a}-\beta_{t a} / T\right)}\right)\right)\left[e^{-\left(e^{\left(\alpha_{t a}-\beta_{t a} / T\right)}\right) t}-e^{-\left(e^{\left(\alpha_{2}-\beta_{2} / T\right)}\right) t}\right]} .
$$

In this equation, $[\mathrm{PP}]_{0}$ is the initial concentration of $\mathrm{PP}, T$ is temperature in Kelvin, $t$ is the storage time in hour, and values $\alpha_{1}, \beta_{1}, \alpha_{2}$, and $\beta_{2}$ are related to kinetic constants and are protected by industrial license according to the authors. According to the proposed model, \% PPP at any time point can be calculated if the initial PP and PPP concentration and storage temperature are known.

This study also compared the change of \% PPP under a well-controlled storage temperature of $15^{\circ} \mathrm{C}$ and room temperature for six single-cultivar VOO samples. Overall, \% PPP increased under both temperatures, indicating the degradation of olive oil quality occurred over time in spite of cultivars. However, it is clear that the same samples stored at room temperature had a significant increase in \% PPP from 0 to above $8 \%$, especially during summer time (6-8 storage months) when room temperature was typically higher. The development of this parameter tended to be linear with a smaller slope (from 0 to $2 \%$ ) throughout the entire storage period at $15^{\circ} \mathrm{C}$. This finding confirms the temperature impact on PPP generation over time which should be taken into consideration when developing the kinetic model.

After being validated on and compared with another set of empirical data calculated from chlorophyll pigment experimental data obtained by Gallardo-Guerrero, et al. [46], the model was adopted to develop a \% PPP prediction graph between $15^{\circ} \mathrm{C}$ and $35^{\circ} \mathrm{C}$ as shown in Figure 4 . The authors suggested that the \% PPP acceptable limit could be set at $14 \%$, which would allow VOO to have one year of shelf life if stored under $22^{\circ} \mathrm{C}$. However, this value seems arbitrary as it did take into account any other chemical parameters and/or sensory results.

In a follow-up study published in 2014 [47], the same research team applied this \% PPP prediction model to singlecultivar olive oils (Arbequina $c v$ ) with various levels of initial $\%$ PPP at bottling. The samples were stored at different average annual temperatures, ranging from $10^{\circ} \mathrm{C}$ to $16^{\circ} \mathrm{C}$. The authors concluded that the initial value of \% PPP is of great importance to be included for a better monitoring of the storage conditions of VOO. Table 7 shows shelf life (in months) for $\mathrm{VOO}$ samples stored at $10^{\circ} \mathrm{C}$ and $16^{\circ} \mathrm{C}$ before reaching the Australian/California upper limit for PPP of $17 \%$. For instance, if \% PPP is $0.64 \%$ at bottling, the oil will have more than 36 months and 21 months before it reaches the limit of $17 \%$ if stored at $10^{\circ} \mathrm{C}$ and $16^{\circ} \mathrm{C}$, respectively. These temperatures are likely to be cooler than the actual storage temperature; thus a follow-up study with oil stored at a typical store shelf temperature is recommended.

This model only consists of two chlorophyll pigments (PP and PPP) and can be used to monitor the changes of storage temperature and to detect undesired storage conditions based on the rate of pyropheophytinization. Knowing the value of \% PPP at any moment during a storage period would also allow a timely adjustment on proper storage temperature and later on provide a better shelf-life estimation. However, without knowing the values of other quality parameters of VOO samples, the \% PPP alone may not reflect the storage condition correctly as light exposure can cause the complete breakdown of chlorophylls and all of its derivatives therefore yield a zero value of \% PPP [59]. Hence, inclusion of other quality parameters of samples would benefit the model optimization.

2.8. Farhoosh and Hoseini-Yazdi (2013) [25]. The empirical model was developed based on the relationship between oxidative stability measurements (OSI) taken at high temperatures $\left(100-130^{\circ} \mathrm{C}\right)$ and the chemical composition data obtained at a low temperature $\left(50^{\circ} \mathrm{C}\right)$.

To study the contribution of each compositional parameter to the oxidative stability in olive oil, nine olive oil samples in $1 \mathrm{~L}$ glass bottles were purchased from local shops and stored at $4^{\circ} \mathrm{C}$ until analysis on accelerated stability at $100-130^{\circ} \mathrm{C}$. And the ratios between mono- and polyunsaturated fatty acids (M/P ratio), PV and FFA, total tocopherols (TT) and total phenols (TP), total polar compounds (TPC), conjugated diene value (CDV), and induction period (IP) were tested for the storage stability on the same samples incubated at $50^{\circ} \mathrm{C}$. 
TABLE 7: Shelf life (in months) for VOO stored at $10^{\circ} \mathrm{C}$ and $16^{\circ} \mathrm{C}$ before reaching Australian/California limit of $17 \%$ summarized from Aparicio-Ruiz et al. (2014).

\begin{tabular}{lcc}
\hline \% PPP at bottling & $\begin{array}{c}\text { Shelf life if stored at } \\
10^{\circ} \mathrm{C}\end{array}$ & $\begin{array}{c}\text { Shelf life if stored at } \\
16^{\circ} \mathrm{C}\end{array}$ \\
\hline 0.64 & $>36$ & 21 \\
1.35 & $>36$ & 20 \\
3.26 & $>36$ & 19 \\
7.06 & 34 & 16 \\
8.66 & 30 & 10 \\
\hline
\end{tabular}

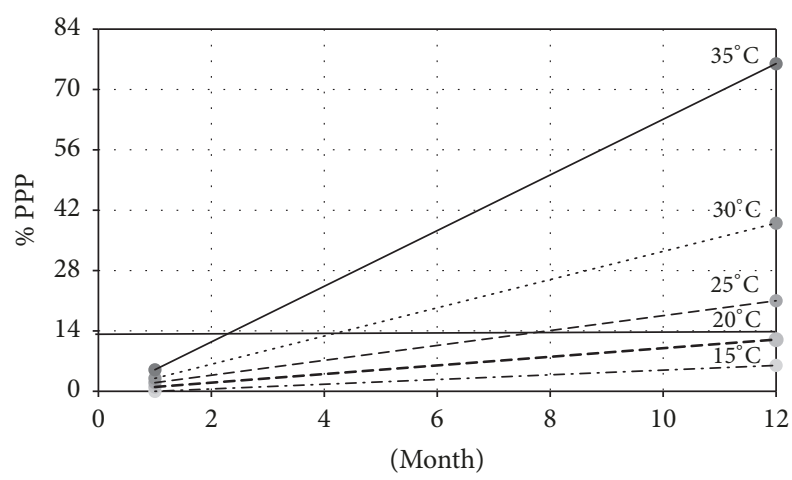

Figure 4: Predicted \% PPP during one year of storage at temperatures between $15^{\circ} \mathrm{C}$ and $35^{\circ} \mathrm{C}$ adopted from Aparicio-Ruiz et al. (2012) [16]\}.

During the storage stability test conducted at $50^{\circ} \mathrm{C}$, the evolution of hydroperoxides and conjugated dienes showed two pseudo zero-order kinetic curves: a gradual slope of linear stage which was considered as the initiation phase of lipid oxidation and then a steep slope of another linear stage known as the propagation phase. The storage time (in days) at intersection points of the PV and CDV curves was identified as the induction period $\mathrm{IP}_{\mathrm{PV}}$ and $\mathrm{IP}_{\mathrm{CDV}}$ for the olive oil sample. The level of hydroperoxides increased gradually during IP and then elevated rapidly in the propagation phase, where decomposition of hydroperoxides to aldehydes, ketones, and other secondary oxidative products occurred and off-flavors were accumulated [15]. Thus, the IP-based oxidative stability values $\mathrm{IP}_{\mathrm{PV}}$ and $\mathrm{IP}_{\mathrm{CDV}}$ were selected as better parameters to measure the oxidative stability and determine the shelf life of olive oil at $50^{\circ} \mathrm{C}$.

Positive correlations were found between oxidative stability $\left(\mathrm{IP}_{\mathrm{CDV}}\right.$ at $50^{\circ} \mathrm{C}$ and $\mathrm{OSI}$ at $\left.100-130^{\circ} \mathrm{C}\right)$ and $\mathrm{M} / \mathrm{P}$ ratio, tocopherols, and phenolics. To further elucidate, the higher the $\mathrm{M} / \mathrm{P}$ ratio is, the less prone to rancidity the olive oil is; the higher the content of tocopherols and/or phenolics of the oil is, the better the antioxidative ability the oil has. It is worth mentioning that the order of the IP-based oxidative stability of olive oil samples at $50^{\circ} \mathrm{C}$ was sample $7>2>6 \approx 3>$ $9>4 \approx 1>8>5$, whereas the order of that determined by the OSI from the accelerated stability test at $100-130^{\circ} \mathrm{C}$ followed sample $7>9>3>8>6 \approx 2 \approx 1>5>4$. The difference may be indicative of the fact that the extrapolation from the OSI obtained at accelerated temperature to ambient conditions could lead to over- or underprediction of the actual shelf life due to complicated kinetics involved at higher temperature $[24,33]$.

Regression models developed under low- (model (a)) and high-temperature (model (b)) were also provided based on the analytical data generated from either condition. By incorporating the chemical composition data collected at $50^{\circ} \mathrm{C}$ into the OSI measurement at $100-130^{\circ} \mathrm{C}$, an empirical model (c) of shelf-life prediction $\left(\mathrm{SL}_{50}\right)$ was derived from model (a) and model (b):

$$
\text { (a) } \mathrm{SL}_{50}=24.0639\left(\sum_{i=1}^{3} C_{i} * S_{i}\right)+104.7369 \text {, }
$$

where $C_{i}$ and $S_{i}$ are regression coefficients and standardized compositional variables.

$$
\text { (b) } \mathrm{SL}_{50}=10^{(50 s+i-1.2272)} \text {, }
$$

where $s$ and $i$ values are slopes and intercept of the linear equation to the log OSI versus accelerated temperature.

$$
\begin{aligned}
& \text { (c) } \mathrm{SL}_{50}=0.9985\left\{A\left(\frac{100-a_{0}}{100 a}\right)(\mathrm{OSI}-b)\right. \\
& \left.+A \frac{a_{1}((b-\mathrm{OSI}) / 100 a)}{1+\left(\left(\mathrm{OSI}-b-a a_{2}\right) / a a_{3}\right)^{2}}+B\right\},
\end{aligned}
$$

where $a, b, A$, and $B$ are the values of the linear regression models developed at high and low temperatures, respectively. The values of $a_{0}, a_{1}, a_{2}$, and $a_{3}$ were calculated and shown in Table 8. According to the conclusion of $Q_{10}$ factor from Mancebo-Campos et al. [23], which is that a decrease of $10^{\circ} \mathrm{C}$ in the storage temperature increases the shelf life of olive oil more than two folds, a value of 2.1 of $Q_{10}$ was used to estimate the oil shelf life at $25^{\circ} \mathrm{C}$ (normal storage temperature) by using the regression model (a) and promising estimation was obtained (13.1-22.2 months) which was considered to be representative of the typical shelf life claimed by olive oil producers (12-18 months after production).

Model (c) permitted the estimation of olive oil shelf life to be achieved within acceptable errors less than $\pm 10 \%$ by using only one measurement, OSI, at accelerated temperatures. The interrelated mathematical equation of the low- and hightemperature regression models also allows real-time shelflife prediction from the accelerated testing results to be done rapidly. A limitation of this model is that only two EVOO samples were analyzed; without performing further validation on the empirical model on a larger size of EVOO samples, the calculated values provided in Table 8 and the correction coefficient of 0.9985 may considerably deviate and not reflect the actual situation of EVOO category.

2.9. Guillaume and Ravetti (2016) [18]. This empirical model uses four quality parameters, induction time, DAGs, FFA Factor (derived from FFA), and PPP, to identify a best before 
TABLE 8: The values of $a_{0}, a_{1}, a_{2}$, and $a_{3}$ in the $\mathrm{SL}_{50}$ prediction model calculated at $100^{\circ} \mathrm{C}$ and $130^{\circ} \mathrm{C}$ by Farhoosh and Hoseini-Yazdi (2013).

\begin{tabular}{lcccc}
\hline Temperature $\left({ }^{\circ} \mathrm{C}\right)$ & $a_{0}$ & $a_{1}$ & $a_{2}$ & $a_{3}$ \\
\hline 100 & -174.4761 & -201.4675 & 32898.6507 & 19757.9412 \\
130 & 0.0108 & 0.0230 & -0.0106 & 0.0190 \\
\hline
\end{tabular}

date (BBD, in months) using the lowest value obtained from the following three equations:

(a) Hours of induction time at $110^{\circ} \mathrm{C}$

(b) $\frac{\text { DAGs }-35 \%}{\text { FFA Factor }}$

FFA factor $=1.7 \%($ if $\mathrm{FFA}<0.4 \%) ; 2.1 \%($ if $\mathrm{FFA}>0.4 \%$ and $<0.6 \%$ ); or $2.5 \%$ (if FFA $>0.6 \%$ ):

$$
\text { (c) } \frac{17 \%-\mathrm{PPPs}}{0.6 \%}
$$

This model recognizes that induction time generally correlates with olive oil FAPs and antioxidant content. DAGs and PPP have been shown to be predictable and change linearly with time whereas FFA provides a value for the initial oil quality and does not change significantly under proper storage conditions. These four quality parameters represent factors that can affect olive oil shelf life over time.

To evaluate this empirical model, the research team analyzed 118 samples for FFA, PV, UV, PPP, DAGs, and sensory evaluation during a 30 -month storage period. The samples were stored in a dark environment at $18^{\circ} \mathrm{C} \pm 2^{\circ} \mathrm{C}$, and tested immediately after reaching their estimated best before date. Of the 118 samples, only one sample $(0.8 \%$ of total samples) exceeded the Australian limit of $0.8 \%$ for FFA; no sample failed the Australian limit for PV $\left(20 \mathrm{meq} \mathrm{O}_{2} / \mathrm{kg}\right)$ or $K_{232}\left(2.50 \mathrm{~K}^{1 \%}{ }_{1 \mathrm{~cm}}\right)$; two samples $(1.7 \%)$ failed $K_{270}$ limit $\left(0.22 \mathrm{~K}^{1 \%}{ }_{1 \mathrm{~cm}}\right)$; twelve samples $(10.2 \%)$ failed the Australian limit of $17 \%$ for PPP; six samples (5.1\%) failed the Australian limit of 35\% for DAGs; and ten samples (8.5\%) failed sensory evaluation. In addition to testing 118 samples at the end of shelf life under controlled storage condition, 20 samples with predicted shelf life were randomly collected from different retailers every three months during a 30-month storage period to validate the model from retailers' standpoint (200 samples in total). Only one sample ( $0.5 \%$ out of 200 samples) exceeded the limit for $K_{270}$ and two samples (1\%) exceeded the limit for DAGs at their predicted BBD. By recalculating and comparing the actual and predicted $\mathrm{BBD}$, the data suggested that producers may want to deduct 1-2 months from the BBD given from the model to compensate for the potential exposure to heat and light during transportation, handling, storage, and display on the retail shelves.

This model was validated on a total of 318 samples, including 200 commercial samples from real-time storage conditions on the market, with simple and straightforward calculations and yielded clear output. Modifications to the predicted $\mathrm{BBD}$ are necessary when storage condition is not ideal; however, this would be true for any models that are designed for the ideal packaging and storage conditions for olive oil shelf life (Table 9).
TABLE 9: Recommended packaging and storage conditions for olive oil shelf life.

\begin{tabular}{|c|c|c|}
\hline Packaging & Temperature & Light \\
\hline $\begin{array}{l}\text { Dark glass, aluminum cans with } \\
\text { food-grade enamel coating, coated } \\
\text { paperboard, and bag-in-box provide } \\
\text { protection from light and oxygen. } \\
\text { Bag-in-box also has the advantage of } \\
\text { maintaining minimum oxygen in } \\
\text { headspace [14] }\end{array}$ & $\begin{array}{l}\text { Stored at a } \\
\text { reduced } \\
\text { temperature } \\
\text { of } 15^{\circ} \mathrm{C}[29]\end{array}$ & $\begin{array}{c}\text { Stored in } \\
\text { the dark to } \\
\text { minimize } \\
\text { light } \\
\text { exposure }\end{array}$ \\
\hline
\end{tabular}

2.10. Rodrigues et al. (2017) [38]. Coupled with powerful statistical linear discriminant analysis (LDA) $[49,50]$ and simulated annealing (SA) variable selection algorithm approach [51-53], a most recent study on the evaluation of EVOO shelf life was conducted by applying a potentiometric electronic tongue (E-tongue) with nonspecific cross-sensitivity lipid membranes to assess the commercial storage conditions including light exposure and storage time.

The research group had analyzed 36 amber glass-bottled EVOO samples on sensory attributors (conducted by four trained panelists to classify samples based on olfactory sensations, gustatory-retronasal sensations, and final olfactorygustatory sensations), physicochemical parameters (FFA, UV, and PV) and oxidative stability (OSI), and electrochemical signal profiles (E-tongue device with two print-screen potentiometric arrays containing 20 sensors on each one). To further elucidate the sample storage and testing conditions, four fresh samples were analyzed immediately after processing at T0 (0 month) while 32 samples were kept under room temperature $\left(17-25^{\circ} \mathrm{C}\right)$ for one year in the lab, with 16 samples being stored in dark and 16 samples being exposed to natural light and artificial light $(14 \mathrm{~h} /$ day from eight fluorescent lamps) to create a $2 \times 4 \times 4$ experimental factorial design. During the one-year storage period, four samples were taken out and analyzed every three months at time points of T3, T6, $\mathrm{T} 9$, and $\mathrm{T} 12$. As a result, the quality parameters and oxidative stability of the tested EVOO samples were indeed affected by both the storage time and light conditions. It was inferred by the authors that, being stored in amber bottles, light conditions played less significant role on the olive oil quality deterioration during the storage period. In addition, not all the positive attributors of EVOO samples were affected by the storage conditions after one-year storage period, although samples exposed to light showed the strongest correlations among the respective sensory attributors $(R$-Pearson $\geq 0.80)$.

To evaluate the possibility of correctly categorizing olive oil samples based on storage time and/or light conditions (dark/light), the Kennard-Stone selection algorithm (a uniform mapping algorithm that generates a flat distribution of data suitable for regression model development) [56] 
TABLE 10: Summary of statistical analysis performed by Rodrigues et al. (2017).

\begin{tabular}{|c|c|c|}
\hline Objective & Statistical analysis ${ }^{*}$ & $\begin{array}{c}\text { Statistical } \\
\text { analysis ref. }\end{array}$ \\
\hline $\begin{array}{l}\text { Compare the impact of dark/light storage conditions on olive oils for each } \\
\text { storage time }\end{array}$ & Student's $t$-test & {$[48]$} \\
\hline Assess the effect of the storage time on olive oils stored in dark/light & $\begin{array}{l}\text { One-way ANOVA, Tukey's post hoc } \\
\text { multicomparison test }\end{array}$ & {$[48]$} \\
\hline $\begin{array}{l}\text { Evaluate the existence of bivariate correlations within the olive oil's } \\
\text { physicochemical parameters }\end{array}$ & $\begin{array}{l}\text { Linear Pearson correlation coefficient } \\
\text { (R-Pearson) }\end{array}$ & {$[48]$} \\
\hline $\begin{array}{l}\text { Test the capability of the E-tongue to correctly classify the EVOO based on } \\
\text { storage time or storage conditions as a supervised pattern recognition } \\
\text { method }\end{array}$ & Linear discriminant analysis (LDA) & {$[49,50]$} \\
\hline $\begin{array}{l}\text { Evaluate the qualitative classification capability of physicochemical and } \\
\text { sensory data }\end{array}$ & LDA & {$[49,50]$} \\
\hline $\begin{array}{l}\text { Select the best subsets of } K \text { independent predictors among } 40 \text { E-tongue } \\
\text { potentiometric signals }\end{array}$ & $\begin{array}{l}\text { Metaheuristic simulated annealing (SA) } \\
\text { variable selection algorithm }\end{array}$ & {$[51-53]$} \\
\hline Compare the current and the new subsets of $k(\subseteq K)$ variables & Tau2 quality criterion & {$[51]$} \\
\hline Evaluate the LDA classification models & Leave-one-out cross-validation (LOO-CV) & {$[54,55]$} \\
\hline \multirow{2}{*}{$\begin{array}{l}\text { Minimize the risk of overfitting from LOO-CV when sample size is large } \\
\text { and generate a flat distribution of data for regression model development }\end{array}$} & $\begin{array}{l}24 \text { olive oil samples used as "training set” for } \\
\text { LOO-CV }\end{array}$ & {$[54,55]$} \\
\hline & $\begin{array}{l}12 \text { olive oil samples used as "testing set" using } \\
\text { Kennard-Stone algorithm }\end{array}$ & {$[56]$} \\
\hline
\end{tabular}

was adopted by splitting 36 bottled olive oil samples into two subsets (24 for internal validation and 12 for external validation). By applying the metaheuristic SA variable selection algorithm, the best subset to be included in each LDA model was selected from physicochemical parameters, sensory attributors, and E-tongue signal profiles for the determination of the effect of different storage conditions on the quality of EVOO samples. The internal validation statistical data showed that E-tongue signal profiles yielded an overall better predictive discrimination performance, enabling the establishment of three best LDA-SA prediction models (from 5 to 8 sensor/sensor-replicas as independent variables) without redundant variables. The external validation further justified the predictive capability of E-tongue by giving a representative fingerprint of the polar compounds in olive oil samples.

As a promising chemometric approach, combining Etongue measurement and comprehensive statistical analysis (Table 10) could successfully determine the freshness of EVOO samples during normal commercial storage conditions (stored in dark or exposed to light for one year) and provide accurate shelf-life prediction. Nonetheless, it is important and necessary that at least eight trained panelists were presented to provide sensory data as the lack of sensory data could significantly influence the statistical analysis results.

\section{Conclusion}

The global production and consumption of olive oil has escalated significantly in the past decade [60]. According to the IOC Market Newsletter released in September, 2017, the producer prices of EVOO have increased by more than $15 \%$ (in euros) in Spain, Italy, Tunisia, and Greece compared to the same period in the previous year [61]. Thus, to maintain the high quality of EVOO products during commercial activities has become an urgent matter to olive oil producers and being able to accurately predict the shelf life of EVOO products would greatly benefit both producers and consumers.

EVOO quality can be safeguarded by using proper packaging, ideal storage conditions (cool and dark), and having an accurate best before date. Currently in literature, common parameters that are being used to track the changes in olive oil include FFA, PV, UV, DAGs, PPP, sensory evaluation, induction time, FAP, total tocopherols and total phenols, and volatiles. A mathematical model for tracking deterioration using sensitive and accurate quality parameters can be a powerful and affordable tool for accurately predicting olive oil shelf life.

In this review, ten practical mathematical models that have potential to be adopted and utilized by olive oil producers are summarized. Nonetheless, each of the models can benefit from further study with a large set of samples under real-life transport and storage conditions, monitoring both compositional and environmental variables. To establish a robust and systematic model for shelf life assessment, the most urgent tasks are (1) to remove unnecessary parameters and to confirm the acceptable limits without losing the predictability and accuracy and (2) to continue developing and fine-tuning accelerated methods to minimize their tendency for overprediction or underprediction of actual shelf life. By reducing inessential parameters used in a model, the processing time and cost of shelf life assessment are also reduced. Since sensory evaluation remains to be one 
of the most sensitive methods for olive oil quality and freshness, a working model should be calibrated with sensory evaluation and complement sensory evaluation for olive oil freshness assessment in the future. Temperature, airflow rate, and oil sample size have significant impacts on shelf life prediction when using accelerated methods. It is critical to adjust and optimize the operational settings to minimize the discrepancy between the real-time shelf life and accelerated prediction of an EVOO product.

\section{Conflicts of Interest}

The authors declare that there are no conflicts of interest regarding the publication of this paper.

\section{Acknowledgments}

This review was made possible with the financial support from the Olive Oil Commission of California. The authors would also like to thank Leandro Ravetti and Dan Flynn for helpful discussions.

\section{References}

[1] S. Teres, G. Barceló-Coblijn, M. Benet et al., "Oleic acid content is responsible for the reduction in blood pressure induced by olive oil," Proceedings of the National Acadamy of Sciences of the United States of America, vol. 105, no. 37, pp. 13811-13816, 2008.

[2] R. W. Owen, A. Giacosa, W. E. Hull, R. Haubner, B. Spiegelhalder, and H. Bartsch, "The antioxidant/anticancer potential of phenolic compounds isolated from olive oil," European Journal of Cancer, vol. 36, no. 10, pp. 1235-1247, 2000.

[3] H. L. Newmark, "Squalene, olive oil, and cancer risk: a review and hypothesis," Cancer Epidemiology, Biomarkers \& Prevention, vol. 6, no. 12, pp. 1101-1103, 1997.

[4] R. Mateos, M. M. Domínguez, J. L. Espartero, and A. Cert, "Antioxidant Effect of Phenolic Compounds, $\alpha$-Tocopherol, and Other Minor Components in Virgin Olive Oil," Journal of Agricultural and Food Chemistry, vol. 51, no. 24, pp. 7170-7175, 2003.

[5] F. Angerosa, R. Mostallino, C. Basti, and R. Vito, "Virgin olive oil odour notes: Their relationships with volatile compounds from the lipoxygenase pathway and secoiridoid compounds," Food Chemistry, vol. 68, no. 3, pp. 283-287, 2000.

[6] A. M. Inarejos-García, S. Gómez-Alonso, G. Fregapane, and M. D. Salvador, "Evaluation of minor components, sensory characteristics and quality of virgin olive oil by near infrared (NIR) spectroscopy," Food Research International, vol. 50, no. 1, pp. 250-258, 2013.

[7] F. Angerosa, M. Servili, R. Selvaggini, A. Taticchi, S. Esposto, and G. Montedoro, "Volatile compounds in virgin olive oil: Occurrence and their relationship with the quality," Journal of Chromatography A, vol. 1054, no. 1-2, pp. 17-31, 2004.

[8] S. Fadiloglu and Z. Soylemez, "Kinetics of lipase-catalyzed hydrolysis of olive oil," Food Research International, vol. 30, no. 3-4, pp. 171-175, 1997.

[9] E. Frankel, Lipid Oxidation, Elsevier, 2014.

[10] B. Zanoni, M. Bertuccioli, P. Rovellini, F. Marotta, and A. Mattei, "A preliminary approach to predictive modelling of extra virgin olive oil stability," Journal of the Science of Food and Agriculture, vol. 85, no. 9, pp. 1492-1498, 2005.

[11] A. Kiritsakis, G. D. Nanos, Z. Polymenopoulos, T. Thomai, and E. M. Sfakiotakis, "Effect of fruit storage conditions on olive oil quality," Journal of the American Oil Chemists' Society, vol. 75, no. 6, pp. 721-724, 1998.

[12] L. Di Giovacchino, M. Solinas, and M. Miccoli, "Effect of extraction systems on the quality of virgin olive oil," Journal of the American Oil Chemists' Society, vol. 71, no. 11, pp. 1189-1194, 1994.

[13] G. Pristouri, A. Badeka, and M. G. Kontominas, "Effect of packaging material headspace, oxygen and light transmission, temperature and storage time on quality characteristics of extra virgin olive oil," Food Control, vol. 21, no. 4, pp. 412-418, 2010.

[14] S. Wang, X. Li, R. Rodrigues, and D. Flynn, Packaging Influences on Olive Oil Quality: A Review of The Literature, UC Davis Olive Center, 2014.

[15] X. Li, H. Zhu, C. F. Shoemaker, and S. C. Wang, "The effect of different cold storage conditions on the compositions of extra virgin olive oil," Journal of the American Oil Chemists' Society, vol. 91, no. 9, pp. 1559-1570, 2014.

[16] R. Aparicio-Ruiz, M. Roca, and B. Gandul-Rojas, "Mathematical model to predict the formation of pyropheophytin a in virgin olive oil during storage," Journal of Agricultural and Food Chemistry, vol. 60, no. 28, pp. 7040-7049, 2012.

[17] N. Sinelli, M. S. Cosio, C. Gigliotti, and E. Casiraghi, "Preliminary study on application of mid infrared spectroscopy for the evaluation of the virgin olive oil "freshness"," Analytica Chimica Acta, vol. 598, no. 1, pp. 128-134, 2007.

[18] C. Guillaume and L. Ravetti, "Shelf-Life Prediction of Extra Virgin Olive Oils Using an Empirical Model Based on Standard Quality Tests," Journal of Chemistry, vol. 2016, Article ID 6393962, 2016.

[19] E. Psomiadou, K. X. Karakostas, G. Blekas, M. Z. Tsimidou, and D. Boskou, "Proposed parameters for monitoring quality of virgin olive oil (Koroneiki cv)," European Journal of Lipid Science and Technology, vol. 105, no. 8, pp. 403-408, 2003.

[20] E. Pagliarini, B. Zanoni, and G. Giovanelli, "Predictive study on tuscan extra virgin olive oil stability under several commercial conditions," Journal of Agricultural and Food Chemistry, vol. 48, no. 4, pp. 1345-1351, 2000.

[21] M. Nicoli, The Shelf Life Assessment Process, CRC Press, Boca Raton, Fla, USA, 2012.

[22] A. Kanavouras, P. Hernandez-Munoz, and F. A. Coutelieris, "Packaging of olive oil: quality issues and shelf life predictions," Food Reviews International, vol. 22, no. 4, pp. 381-404, 2006.

[23] V. Mancebo-Campos, G. Fregapane, and M. D. Salvador, "Kinetic study for the development of an accelerated oxidative stability test to estimate virgin olive oil potential shelf life," European Journal of Lipid Science and Technology, vol. 110, no. 10, pp. 969-976, 2008.

[24] A. Kaya, A. R. Tekin, and M. D. Öner, "Oxidative stability of sunflower and olive oils: comparison between a modified active oxygen method and long term storage," LWT-Food Science and Technology, vol. 26, no. 5, pp. 464-468, 1993.

[25] R. Farhoosh and S.-Z. Hoseini-Yazdi, "Shelf-life prediction of olive oils using empirical models developed at low and high temperatures," Food Chemistry, vol. 141, no. 1, pp. 557-565, 2013.

[26] A. Kanavouras, P. Hernandez-Münoz, F. Coutelieris, and S. Selke, "Oxidation-derived flavor compounds as quality indicators for packaged olive oil," Journal of the American Oil Chemists' Society, vol. 81, no. 3, pp. 251-257, 2004. 
[27] S. Dabbou, I. Gharbi, S. Dabbou, F. Brahmi, A. Nakbi, and M. Hammami, "Impact of packaging material and storage time on olive oil quality," African Journal of Biotechnology, vol. 10, no. 74, pp. 16937-16947, 2011.

[28] D. A. Tsimis and N. G. Karakasides, "How the choice of container affects olive oil quality - A review," Packaging Technology and Science, vol. 15, no. 3, pp. 147-154, 2002.

[29] D. Krichene, M. D. Salvador, and G. Fregapane, "Stability of virgin olive oil phenolic compounds during long-term storage (18 months) at temperatures of 5-50 C," Journal of Agricultural and Food Chemistry, vol. 63, no. 30, pp. 6779-6786, 2015.

[30] A. I. Méndez and E. Falqué, "Effect of storage time and container type on the quality of extra-virgin olive oil," Food Control, vol. 18, no. 5, pp. 521-529, 2007.

[31] L. Rastrelli, S. Passi, F. Ippolito, G. Vacca, and F. de Simone, "Rate of degradation of $\alpha$-tocopherol, squalene, phenolics, and polyunsaturated fatty acids in olive oil during different storage conditions," Journal of Agricultural and Food Chemistry, vol. 50, no. 20, pp. 5566-5570, 2002.

[32] IOC, Trade Standard Applying to Olive Oils and Olive Pomace Oils, COI/T.15/NC No 3/Rev. 11, 2016.

[33] E. N. Frankel, "In search of better methods to evaluate natural antioxidants and oxidative stability in food lipids," Trends in Food Science \& Technology, vol. 4, no. 7, pp. 220-225, 1993.

[34] F. A. Coutelieris and A. Kanavouras, "Experimental and theoretical investigation of packaged olive oil: development of a quality indicator based on mathematical predictions," Journal of Food Engineering, vol. 73, no. 1, pp. 85-92, 2006.

[35] F. Gutiérrez and J. L. Fernández, "Determinant parameters and components in the storage of virgin olive oil. Prediction of storage time beyond which the oil is no longer of 'extra' quality," Journal of Agricultural and Food Chemistry, vol. 50, no. 3, pp. 571-577, 2002.

[36] A. Kanavouras and F. A. Coutelieris, "Shelf-life predictions for packaged olive oil based on simulations," Food Chemistry, vol. 96, no. 1, pp. 48-55, 2006.

[37] M. B. Brown and A. B. Forsythe, "Robust tests for the equality of variances," Journal of the American Statistical Association, vol. 69, no. 346, pp. 364-367, 1974.

[38] N. Rodrigues, L. G. Dias, A. C. A. Veloso, J. A. Pereira, and A. M. Peres, "Evaluation of extra-virgin olive oils shelf life using an electronic tongue-chemometric approach," European Food Research and Technology, vol. 243, no. 4, pp. 597-607, 2017.

[39] C. M. Kalua, M. S. Allen, D. R. Bedgood Jr., A. G. Bishop, P. D. Prenzler, and K. Robards, "Olive oil volatile compounds, flavour development and quality: a critical review," Food Chemistry, vol. 100, no. 1, pp. 273-286, 2007.

[40] M. T. Morales, J. J. Rios, and R. Aparicio, "Changes in the volatile composition of virgin olive oil during oxidation: Flavors and Off-flavors," Journal of Agricultural and Food Chemistry, vol. 45, no. 7, pp. 2666-2673, 1997.

[41] S. Gómez-Alonso, V. Mancebo-Campos, M. D. Salvador, and G. Fregapane, "Evolution of major and minor components and oxidation indices of virgin olive oil during 21 months storage at room temperature," Food Chemistry, vol. 100, no. 1, pp. 36-42, 2007.

[42] S. A. Vekiari, P. Papadopoulou, and A. Koutsaftakis, "Comparison of different olive oil extraction systems and the effect of storage conditions on the quality of the virgin olive oil," Grasas $y$ Aceites, vol. 53, no. 3, pp. 324-329, 2002.
[43] R. Farhoosh, "The effect of operational parameters of the Rancimat method on the determination of the oxidative stability measures and shelf-life prediction of soybean oil," Journal of the American Oil Chemists' Society, vol. 84, no. 3, pp. 205-209, 2007.

[44] M. Martín-Polvillo, T. Albi, and A. Guinda, "Determination of trace elements in edible vegetable oils by atomic absorption spectrophotometry," Journal of the American Oil Chemists' Society, vol. 71, no. 4, pp. 347-353, 1994.

[45] S. J. Schwartz and J. H. Elbe, "Kinetics of Chlorophyll Degradation to Pyropheophytin in Vegetables," Journal of Food Science, vol. 48, no. 4, pp. 1303-1306, 1983.

[46] L. Gallardo-Guerrero, B. Gandul-Rojas, M. Roca, and M. I. Mínguez-Mosquera, "Effect of storage on the original pigment profile of Spanish virgin olive oil," Journal of the American Oil Chemists' Society, vol. 82, no. 1, pp. 33-39, 2005.

[47] R. Aparicio-Ruiz, R. Aparicio, and D. L. García-González, "Does "best before" date embody extra-virgin olive oil freshness?" Journal of Agricultural and Food Chemistry, vol. 62, no. 3, pp. 554-556, 2014.

[48] M. O’Mahony, Sensory Evaluation Of Food: Statistical Methods and Procedures, CRC Press, Boca Raton, Fla, USA, 1986.

[49] A. J. Izenman, Modern Multivariate Statistical Techniques, Springer, New York, NY, USA, 2008.

[50] J. N. Miller and J. C. Miller, Statistics and Chemometrics for Analytical Chemistry, Pearson Education Limited, England, 2005.

[51] J. Cadima, J. O. Cerdeira, and M. Minhoto, "Computational aspects of algorithms for variable selection in the context of principal components," Computational Statistics \& Data Analysis, vol. 47, no. 2, pp. 225-236, 2004.

[52] S. Kirkpatrick, J. Gelatt, and M. P. Vecchi, "Optimization by simulated annealing," American Association for the Advancement of Science: Science, vol. 220, no. 4598, pp. 671-680, 1983.

[53] D. Bertsimas and J. Tsitsiklis, "Simulated annealing," Statistical Science, vol. 8, no. 1, pp. 10-15, 1993.

[54] L. G. Dias, A. Fernandes, A. C. A. Veloso, A. S. C. Machado, J. A. Pereira, and A. M. Peres, "Single-cultivar extra virgin olive oil classification using a potentiometric electronic tongue," Food Chemistry, vol. 160, pp. 321-329, 2014.

[55] J. M. Gutiérrez, Z. Haddi, A. Amari et al., "Hybrid electronic tongue based on multisensor data fusion for discrimination of beers," Sensors and Actuators B: Chemical, vol. 177, pp. 989-996, 2013.

[56] R. W. Kennard and L. A. Stone, "Computer aided design of experiments," Technometrics, vol. 11, no. 1, pp. 137-148, 1969.

[57] M. Kuhn and K. Johnson, Applied Predictive Modeling, Springer, New York, NY, USA, 2013.

[58] W. N. Venables and B. D. Ripley, Modern Applied Statistics with $S$-PLUS, Springer Science \& Business Media, New York, NY, USA, 2013.

[59] J. Ayton, R. Mailer, and K. Graham, The Effect of Storage Conditions on Extra Virgin Olive Oil Quality, Australian Government Rural Industries Research and Development Corporation, 2012.

[60] B. Lynch and A. Rozema, "Olive oil: conditions of competition between us and major foreign supplier industries," United States International Trade Commission, Wash, USA, 2013.

[61] IOC, September market newsletter No 119, 2017. 


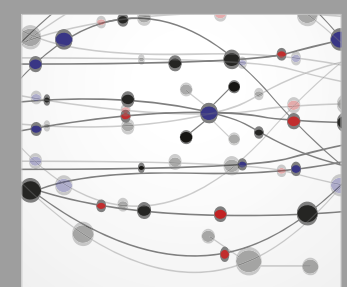

The Scientific World Journal
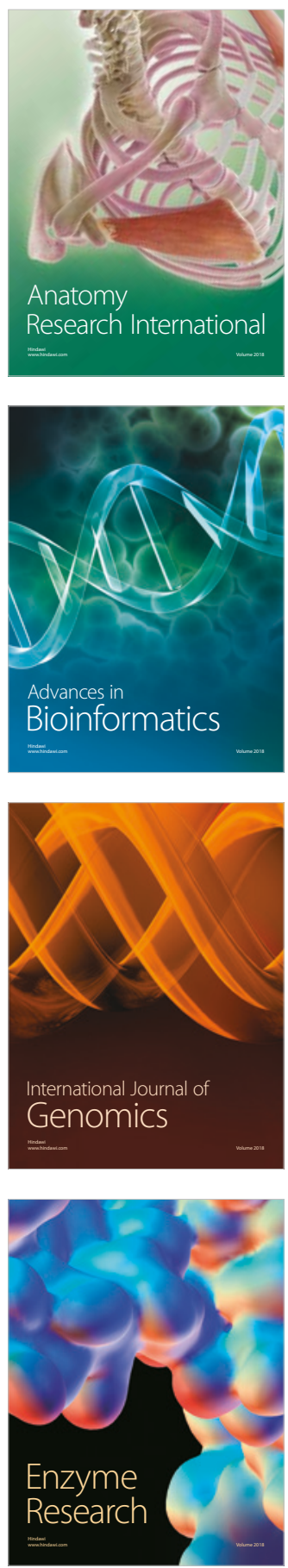
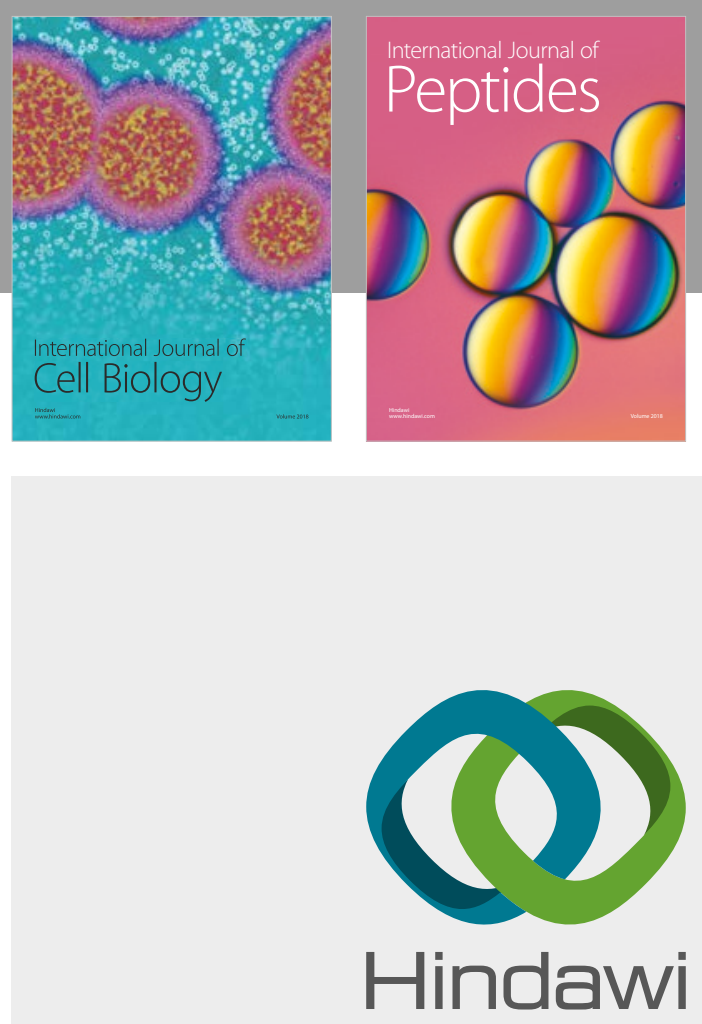

Submit your manuscripts at

www.hindawi.com
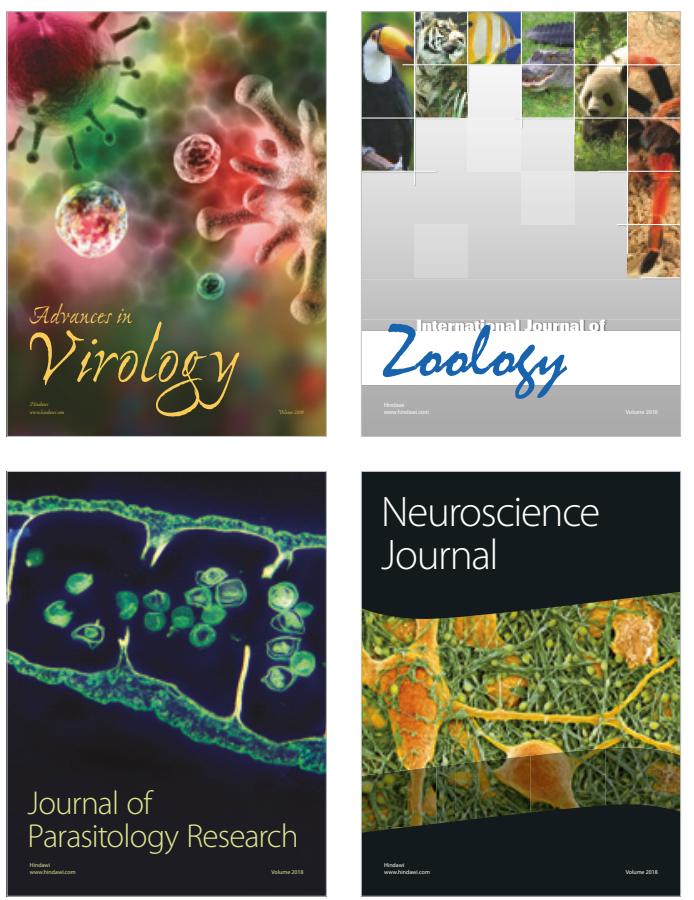
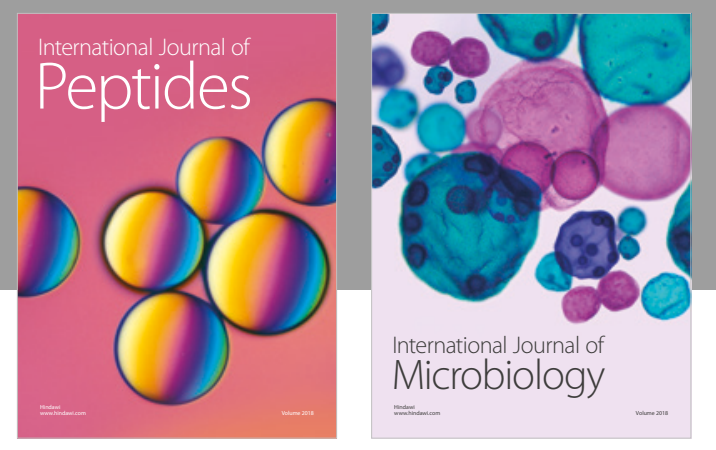

nternational Journal of Microbiology
Journal of
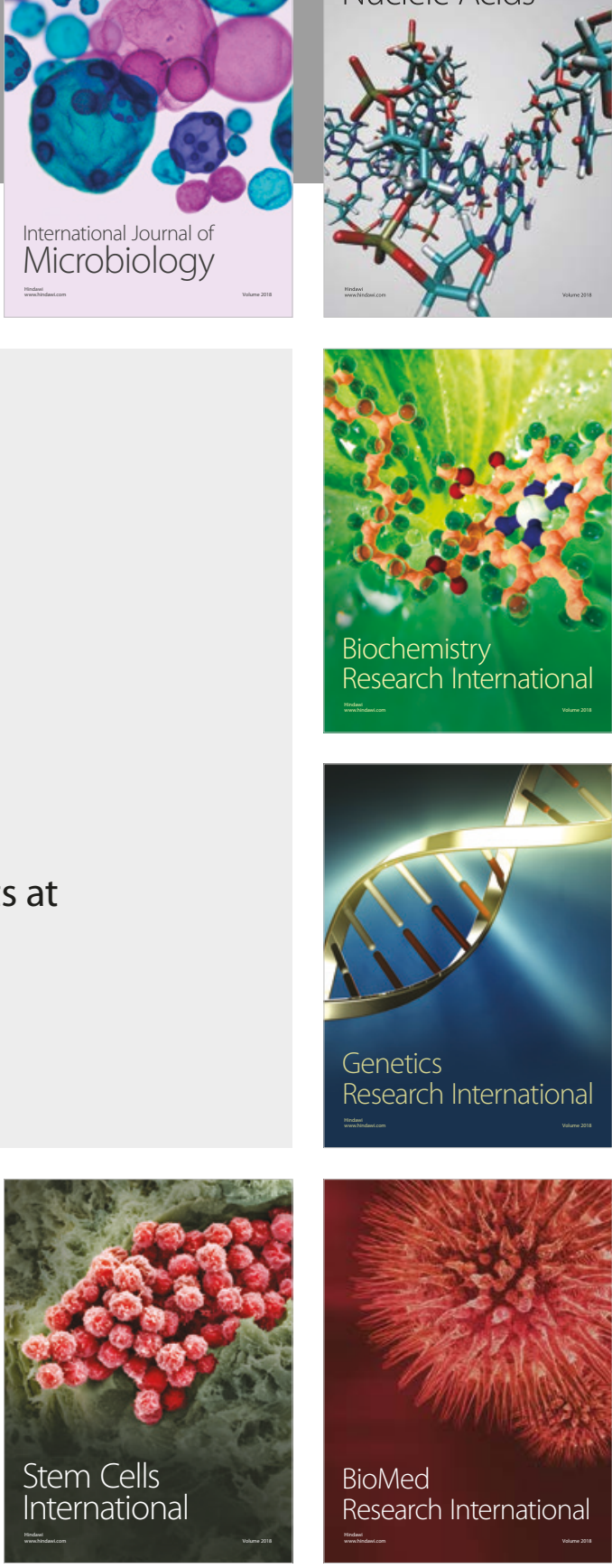
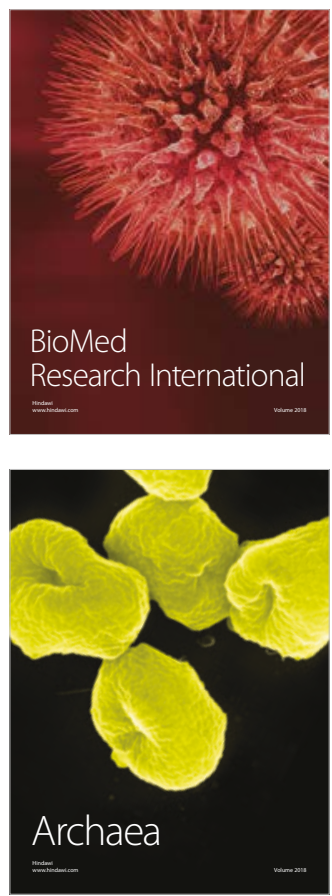